\title{
Bidder and Seller Strategies in Online Auctions: A Review
}

\author{
Audrey Elizabeth Wen ${ }^{1, \dagger}$, HoiYat Wong ${ }^{2, *}, \dagger$ \\ ${ }^{1}$ Dulwich College Beijing, Beijing, China \\ ${ }^{2}$ Tsinghua International School, Beijing, China \\ ${ }^{*}$ Corresponding author. Email: ${ }^{2}$ hoiyat_wong22@this.edu.cn \\ These authors contributed equally.
}

\begin{abstract}
Since the 1990s, online auctions, as well as e-commerce in general, has boomed. The COVID-19 pandemic this year has further led to an increase in online transactions, making the topic of online auctions as current as ever. This paper summarizes and compares existing research on the strategies for bidders and sellers in online auctions to conclude that sniping could be an optimal strategy for bidders to employ and that sellers must take a more strategic approach in selecting discretionary attributes in their auction listings to maximize profits.
\end{abstract}

Keywords: Online Auction, Bidding Strategy, Seller Strategy, Sniping, Buyout Price.

\section{INTRODUCTION}

\subsection{Research Background}

An online auction is a service that allows auction participants or consumers to sell or bid on items through the Internet. Bidders can think about and analyse the transaction before bidding because these things are only displayed for a few days. The number of bids received has increased due to the lack of geographical or temporal limits. Online auctions are less expensive and less expensive than physical auctions. Both buyers and sellers will benefit in this fashion. Sellers gain access to a broader spectrum of clients and can offer greater access and services at a reduced cost. On the other hand, the number of bidders much outnumbers the number of sellers, with 65 per cent bidding one to 10 times and 22 per cent bidding more than 26 times. Customer, company, and business auctions are becoming increasingly common.

In this article, a key example we will discuss is eBay, the main online auction host established in 1995. Due to the auction space provided by eBay, many enterprises have taken off. Before bidding, the bidder should thoroughly study the product description, delivery details, and project image. Technology advancements and the implementation of additional functionality have made online auctions easier than ever before. Developers and software engineers have faced numerous problems and difficulties throughout the development process and the integration of the online auction system. They consider, plan, evaluate, develop, redesign, test, repair errors, and create the most up-to-date online auction system for customers.

The basic processes involved in the online auction system include buyer and seller registration, auction type determination, auction rules, name, product information, price, etc., auction link arrangement (including start and end times), bid collection and verification, auction ends, and finally transaction settlement.

In 1995, there were two distinct auction websites emerged: onsale.com, launched by Jerry Kaplan in May 1995, and eBay, founded by Pierre Omidyar, a French Iranian computer scientist, in September of the same year, both of which used ascending bidding. The network offers novel features such as spreadsheet-based automatic bidding, a search engine that can quickly locate things, and the option for users to view products by category. eBay was the first online auction platform to offer people-to-people sales, unlike on-sale. As a result, eBay is the first online auction platform to significantly increase online transactions. The online auction has substantially enlarged the types of commodities and services that may be bought and sold through the auction mechanism, increased the number of auction techniques available, and introduced new uses for auction in general. Hundreds of websites are dedicated to the practice of online auctions in today's network environment. 


\subsection{Research Significance and Paper}

Online auctions have dominated the market since they were first introduced due to various factors. In 2000, only 5 years after eBay first launched, the National Consumer League (NCL) estimated that around 35.6 million people in the United States were reported to have taken part in eBay auctions. That is around a third of adults who were online at the time. Over the years, eBay's popularity and the popularity of other online auction websites all over the globe, such as Taobao and Yahoo, has only grown, with eBay reporting that they've reached 187 million global active buyers in 2021 . However, with eBay incorporating new functions such as a Buy-Out-Price over the years, many sellers seem to have taken this E-Commerce option instead of the auction format. In fact, the NBER revealed that more than $85 \%$ of eBay listings are not auction-only compared to $0 \%$ 10 years ago. Nevertheless, new auction websites are emerging as a result of the Covid-19 pandemic. Many customarily offline auction industries turned to online auctions as an alternative to their traditional offline auctions, which could no longer be held due to social distancing laws. For example, in the Art industry, the top 3 art auction houses- Sotheby's, Christie's, and Phillipssold US\$596.7 million globally, a 255\% increase from their total online sales in 2019, according to Barron's.

Due to the popularity amongst sellers of Buyoutprices on traditional online auction platforms and the reemergence of Online Auctions in new industries, we have decided to analyse the strategies of consumers and sellers in these online auctions attempting to find an optimal strategy for both. Is the optimal strategy for sellers to include a Buyout price? What is the best strategy for a buyer in online auctions? Therefore, this paper wants to summarize the current research results, compare and analyse the current research status of respective strategies for bidders and sellers in online auctions, and point out the possible development direction of both sides to gain maximum profit. This article will start out by discussing bidder strategies in online auctions, mostly focusing on eBay. Even though the popularity of traditional auctiononly listings on eBay has dwindled in the near years, we believe that the investigation of consumer behaviour in eBay auctions can still serve as a prime example of the strategies typically employed online can then be applied to all online auctions. We will be discussing the effectiveness of the strategies of late bidding (also known as sniping), multiple bids over time, and bidding your valuation. The second part of the discussion is the sellers' strategy, which includes four subcategories: buyout price auction, listing strategy for sellers based on eBay, modelling involving marketing and social factors, and evaluating sellers' online strategy. By utilizing effective techniques, sellers can gain more loyal customers to gain maximum profit. In addition, investigating different cases such as eBay, advertising, a buyout price and so forth, the analysis of sellers' strategy will be more inclusive and diverse, easier to compare and summarize the conclusion. In both sections, we will present the various methods taken by the respective authors to reach certain conclusions and then will analyse and compare the results reached.

\section{LITERATURE REVIEW}

Of the papers published on the keyword "auctions", By performing a simple search on Google Scholar using the keywords of "online auction bidder strategy" and "online auction seller strategy" we can get a rough estimate of the amount of research done on bidder and seller strategies in the broader topic of "online auction".

- "online auction bidder strategy" | "online auction seller strategy" = " other

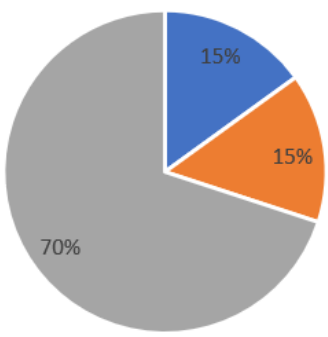

Figure 1. Percentage of results about "online auction bidder strategy" and "online auction seller strategy" in "online auction"

As seen in Figure 1, of the 250,000 results about "online auction", 37,600 and 37,500 results were about "online auction bidder strategy" and "online auction seller strategy", respectively.

Table 1. Publication date and title of papers referenced

\begin{tabular}{lll}
\hline Num. & Date & Title \\
\hline 1 & 2010 & Study on customer's bidding strategies in English online auction. \\
2 & 2016 & Auctions with a buyout price: A survey \\
3 & 2001 & Buy prices in online auctions: irrationality on the internet? \\
4 & 2007 & Temporary and Permanent Buyout Prices in Online Auctions \\
5 & 2000 & Last Minute Bidding and the Rules for Ending Second-Price Auctions: Theory and Evidence from a \\
6 & 2014 & Gatural Experiment on the Internet \\
7 & 2019 & Information Asymmetry among Investors and Strategic Bidding in Peer-to-Peer Lending \\
8 & 2007 & An Analysis of Strategic Behavior in eBay Auctions. \\
9 & 2009 & Sniping and Squatting in Auction Markets \\
10 & 2009 & Snipe bidding behavior in eBay auctions \\
\hline
\end{tabular}




\begin{tabular}{|c|c|c|}
\hline 11 & 2013 & Measuring the Benefits to Sniping on eBay: Evidence from a Field Experiment \\
\hline 12 & 2018 & An Empirical Analysis into the Determinants of eBay Auction Market Closing Prices \\
\hline 13 & 2017 & THE OPTIMAL LISTING STRATEGIES IN ONLINE AUCTIONS \\
\hline 14 & 2017 & The seller's listing strategy in online auctions: Evidence from eBay \\
\hline 15 & 2008 & Buy-Out Prices in Auctions: Seller Competition and Multi-Unit Demands \\
\hline 16 & 2021 & Decision making approaches for an online auction with a permanent buyout option \\
\hline 17 & 2008 & $\begin{array}{l}\text { Dressing Your Online Auction Business for Success: An Experiment Comparing Two eBay } \\
\text { Businesses }\end{array}$ \\
\hline 18 & 2002 & An Optimal Strategy for Sellers in an Online Auction \\
\hline 19 & 2011 & Study on Pricing Model of Online Auction under Competitive Strategy \\
\hline 20 & 2009 & Online Auction Markets \\
\hline 21 & 2019 & A note on stopping strategy of the auction: Maximization seller gain perspective \\
\hline 22 & 2013 & Protection of Consumers in Auction Websites \\
\hline 23 & 2008 & Online Auction Effectiveness: Optimal Selling Strategies for Online Auction Market \\
\hline 24 & 2014 & Seller Strategies for Differentiation in Highly Competitive Online Auction Markets \\
\hline
\end{tabular}

\subsection{Research on Bidders' Strategies in single unit online auctions}

This section will present literature discussing common strategies that buyers on online auction sites use and the overall effectiveness of these strategies. We will consider first auctions with buyout prices and whether the best strategy for bidders then is to use the buyout price or proceed with regular bidding. Then, we will discuss the best strategy for online bidding, particularly focusing on the sniping behaviour and how the results weigh up against traditional strategies.

\subsubsection{Auctions with Buyout Prices for Bidders}

An auction with a buyout price is where the bidder sets a fixed value for the object, and there is the option to buy the object for that value without needing to bid for it. Yang defines the three main categories of buyout auctions as follows: auctions with fixed, temporary, and permanent buyout prices [1]. An auction with a fixedbuyout price is one where the sellers set a buyout price before the auction begins, and the bidders must buy the object at a price set by the seller. This is also known as regular online purchasing, and there is very little research done on this topic as it is very straightforward. First, when the bidder's valuation is less than the buyout price, a bidder's best strategy is to simply not participate in the auction because the bidder's profit would be negative. Second, when the bidder's valuation is greater than the buyout price, the best strategy is to bid the buyout price early. This decreases the possibility of other bidders buying the object before you can [1]. Meanwhile, auctions with temporary buyout prices are ones where the first bidder chooses whether to buy the object immediately at the buyout price or to submit a regular bid above the reserve price and begin a regular auction. If the second option is chosen, the buyout price disappears.

Since bidders here are not the first mover, most studies on this topic focus on auction revenue to discuss whether sellers would implement buyout prices, which we will discuss later on. A few of the papers considering the effect of buyout prices on consumers found that the probability of using the buyout price option highly depended on the individuals themselves. For example, risk-averse bidders and bidders who are in a hurry may be more likely to choose to use the buyout price [2-4]. Otherwise, the paper by Yang assuming risk-neutral bidders concluded that if the valuation of the first bidder is greater than the buyout price and greater than a calculated certain value, then the bidder should choose to use the buyout price. Otherwise, they employ the regular bidding strategy. Auctions with permanent buyout prices have buyout prices that remain throughout the course of the auction. The bidder strategies are very similar to those in auctions with temporary buyout prices, except that throughout the auction, all of the bidders can choose to continue bidding or buy the object at the buyout price. Yang writes that in a permanent auction, if the valuation is above a calculated different certain value that depends on the bidder's values, the bidder should use the buyout strategy. Otherwise, they would bid normally [1]. Meanwhile, Gallien and Gupta believe that a permanent buyout could increase bidders' profits since it incentivises late bidding [4].

\subsubsection{Theory of Online Bidding Strategies: Late Bidding}

The growth of online auctions has led to a considerable number of papers discussing the behaviour of market participants in this new form of auction and how they are affected by auction ending rules. When considering online auctions, observers will quickly notice one particular strategy utilized by many bidders unique to online auctions. This strategy is 'sniping', or, as defined by eBay themselves, "waiting until the last few seconds of an auction to make a winning bid". Also known as "late-bidding", multiple scholars have observed this practice and is undisputed in its existence though a few studies show conflicting levels of behaviour. Due to the prevalence of sniping, many papers have sought to understand why so many bidders, particularly 
on eBay, enlist this strategy and have attempted to investigate how this strategy fares against more traditional strategies such as bidding your valuation. Some earlier studies named irrational behaviour as an explanation for sniping behaviour. However, further research has led many to conclude that there are rational reasons behind sniping behaviour. Roth and Ockenfels compared the prevalence of sniping on Amazon, which employs a non-fixed end time compared to eBay's fixed end time, against eBay, proving that snipers do have a logical reason for sniping on eBay. They introduced a new theory that suggested sniping resulted from players implicitly colluding to avoid bidding wars and that it was a best-response against naïve bidders. By modelling a private value auction, they showed sniping can lead to an equilibrium, and, as long as the probability of your bid being successfully submitted is greater than a certain value, that equilibrium payoff is greater than the payoff of the equilibrium where both players bid their valuation early on [5]. Later studies by Ambrus, Burns, and Ishii agree with Roth and Ockenfels that bidders can implicitly collude by bidding gradually or by waiting to bid until the last minute [6]. Multiple papers have explained how sniping benefits in auctions of objects with commonvalue properties by allowing more informed bidders to avoid giving less informed bidders information about the product's true value. This can theoretically help keep the price of the object down $[5,7]$. This view is, as far as I can tell, completely uncontested. Some later papers like Gonzales and Hasker's, which found empirical data that they took to indicate that bidders are not using the "snipeor-war" strategy suggested by Roth and Ockenfels, even suggested that small changes in the model of the auction to include small common-values could explain the model better [8]. So, while views towards common-value objects are universal, perhaps more research needs to be done on the instance of sniping in private-value auctions.

\subsubsection{Empirical evidence of late bidding vs alternative strategies}

Now that researchers agree that there are rational reasons to snipe, multiple papers have attempted to answer whether sniping is a strategy that bidders should consider actively using in the real world. We will look at this in two ways. Firstly, does sniping increase the probability of winning an auction? Secondly, does sniping increase your surplus compared to alternate strategies? Generally, studies all find that sniping increases the probability of winning the auction. Ely and Hossain found that in two identical auctions, sniping increased the probability of winning an auction by around $9 \%$ compared to the benchmark strategy of squatting (submitting a high initial bid of your valuation at the start of the auction) [9]. Gönül and Leszczyc also found that there is a greater probability of a bidder who is a sniper winning the auction [10]. However, whether sniping results in a lower final price and thus a high surplus for the bidder is more disputed. The study conducted by Ely and Hossain on eBay auctions of DVDs found that though sniping did generally yield a greater payoff compared to squatting, this increase was very small, only around 18 cents which were $1.36 \%$ of their induced valuation [9]. Meanwhile, the study by Gönül and Leszczyc found like implications. They discovered an inverse trend between final price and the estimated probability of sniping, which they took to suggest that for auctions with a lower ending price, there is more likely to have been snipers participating. The exact likelihood and difference in ending prices were not considered. Nevertheless, they concluded that "bidders who want to win an auction and pay the lowest possible price for the item may want to use a sniping strategy." (Gönül and Leszczyc, 2009) [10]. A field experiment by Gray and Reiley also found that, on average, sniping yielded $2.54 \%$ lower prices than squatting, with an average price reduction of $\$ 0.50 \pm \$ 1.00$ [11]. Finally, a study by Halton found that the time that a bid is placed has very little impact on the selling price. In other words, sniping has very little impact on the surplus earned [12]. Therefore, we can generally say that most research shows that sniping increases the probability of winning an auction. However, the surplus gained from sniping is very small on average. Furthermore, this surplus gained is only attributed to the existence of naïve bidders, where sniping is only an optimal strategy against them and not against other sophisticated bidders $[5,9]$.

\subsection{Research on the Seller Strategies in online auctions}

This section will present literature discussing common strategies or auction types that sellers on online auction sites use and discuss the best strategies that sellers should utilize to maximize their profit. Research based on sellers' strategies is divided into three subcategories: buyout price auction, a model involving marketing and social factors, and evaluation on an online auction.

\subsubsection{Auctions with Buyout Prices For sellers}

A buyout price auction was devised to appeal to impatience or risk aversion, allowing bidders to purchase an asset quickly through an online auction. Two ways to categorize buyout price are developed: temporary buyout versus permanent option and still versus dynamic buyout price. Researchers study how buyout pricing can optimize the seller's revenue, the varying benefits achieved by different types of buyout options, and the possible benefit given by dynamic buyout prices that change over time by creating a game-theoretic model. The Nash equilibrium shows that permanent buyout options outperform temporary buyout alternatives in terms of revenue while providing incentives for late bidding [4]. In terms of patience, the perfectly patient 
seller chooses the regular auction; those with a medium range of time impatience are inclined to buy-it-now auction; those who concern the most about time sensitivity adopt fixed price listing [13]. Also, the research brings out how sellers choose these strategies with their respective consequences. In the counterfactual analysis, it is found that find a trade-off between the expected revenue and sale duration for the three listing formats. The ideal reserve price is inversely related to the seller's inter-temporal discount factor within or across listing types. This implies that the optimal reserve price for the buy-it-now auction is greater than that of the regular auction [14]. On the other hand, in comparing still and dynamic buyout auctions, the numerical experience manifests that dynamic options only raise the sellers' utility by a small portion, being ineffective relative to its complexity [15]. In addition, the research compares the decision-making in a permanent online auction of bidders and sellers [16]. However, when other aspects such as many sellers and desired objects are taken into account, the buyout price is found to be inefficient in the auction sequence.

\subsubsection{Model involving marketing and social factors}

Online auctions, which permitted bidding, have evolved into a new trade paradigm based on network technology and auction technology. A seller's goal in an online auction is to sell products for the highest possible profit. Various models and analyses are presented in this area to provide effective tactics while taking social and economic factors into account. Firstly, it examines if a greater e-image quality enhances bidders' willingness to purchase the product; and it concludes that e-image does raise customers' propensity to transact with the firm, as well as boost auction prices [17]. The research then presents an explicit closed-form optimal solution for the seller utilizing convex analysis techniques. This method is distinctively attractive to online auction systems due to its solution to an instant decision, analysis of humanly impossible data, and evaluation of bidders' willingness [18]. A win-win pricing strategy for both internet operators and customers is offered, considering factors such as information flow, corporate objectives, and hazards [19]. A dynamic model of sponsored search advertising auctions is also included in the study, which is an innovative way for allocating premium advertising space to advertisers on prominent websites [20]. Finally, a binomial tree is applied to derive the optimal stopping time for the seller of a commodity. With various instances to highlight the value of theoretical results, it is observed that it is the time point at which a portfolio containing a bond and a call option reaches its maximum [21].

\subsubsection{Evaluation of online auction}

Today, online auction sites such as eBay have grown in popularity, prompting greater review and reflection to improve. The first point of concern is safety. While millions of transactions take place on this auction site every day, the research raises the question of whether auction websites provide adequate consumer protection. Then it provides a better technique for providing consumers with the proper level of protection [22]. The next step is to recognize its significance and conduct a real-world application analysis. The introduction of internet auctions has considerably boosted the number of customers who participate in auctions and the number of businesses attempting to sell their items via auction. The study investigates the outcome of an auction in a genuine marketplace by gathering data from a large number of internet auctions. It goes into greater detail about seller characteristics, auction parameters, the effect of supply and demand, and how these factors affect auction effectiveness [23]. The final stage delves into another topic: seller differentiation in a competitive auction environment, highlighting the online auction's competitive tendency. For example, it investigates the case of eBay and finds that the use of visibility-enhancing and quality-signalling discretionary auction attributes affects auction outcomes throughout the auction process. Furthermore, the results suggest that the number of trustworthy vendors in an auction marketplace moderates the influence of these discretionary traits on auction outcomes. These characteristics, in particular, become increasingly effective instruments for distinction as auction markets become more competitive, but seller feedback scores become less effective. In conclusion, in addition to relying on feedback scores, online sellers must take a more strategic approach in selecting discretionary attributes in their auction listings [24].

\section{CONCLUSION}

Key findings based on research is that when choosing between bidding and buyout in auctions with buyout prices, depending on which option the sellers chose, bidders can make their choice depending on their personal valuation as well as their sensitivity to time and aversion to risk as well. In regular bidding, bidders may consider using the sniping strategy, which, while it doesn't guarantee an increase in expected profit, does have a significant possibility to lead to an increase in profit due to the fact that there are naïve bidders. To obtain the optimal strategy for sellers in online auctions, articles view the competitive online auction market from different perspectives and provide solutions. Specifically, researchers compare different types of actions, mention the reason for the development of online auctions, solve problems existing that bother both consumers and sellers, and analyse the different dynamics of auctions to theoretically get the best result. According to the research statistics, articles about buyout price, modelling with social factors, and evaluation contain the most quantitive number of studies within the range of online auction 
topics. In recent years researches, they prefer to use a model or distinct method containing numerical data analysis to understand corresponding bidders' feedback, or in other words, the efficacy of their method. The topic generates a great value since it considers the sellers' interest and consumers' shown by the example of the protective technique. In addition, the comparison of different strategies provides more possibility for sellers to gain the maximum utility while advancing the online auction system. Although some research includes the factor of the environment, it's mostly inside of the market instead of the social background like coronavirus that boosts all online trade and activity. This article's expectation of the online auction topic is to have more research, including factors of more aspects and focus on more cases other than eBay to give the audience a wider comprehension about the online auction.

\section{REFERENCES}

[1] Mei Yang (2010). Study on customer's bidding strategies in English online auction. Master Dissertation, Nanchang University.

[2] Toshihiro Tsuchihashi (2016). Auctions with a buyout price: A survey. Working paper.

[3] Eric B. Budish \& Lisa N. Takeyama (2001). Buy prices in online auctions: irrationality on the internet? Economics Letters, 2001, vol. 72, issue 3, 325-333

[4] Gallien, J., \& Gupta, S. (2007). Temporary and Permanent Buyout Prices in Online Auctions. $<\mathrm{i}>$ Management Science, $</ \mathrm{i}><\mathrm{i}>53</ \mathrm{i}>(5), 814$ 833. Retrieved September 11, 2021, from http://www.jstor.org/stable/20110742

[5] Roth, Alvin \& Ockenfels, Axel. (2000). Last Minute Bidding and the Rules for Ending Second-Price Auctions: Theory and Evidence from a Natural Experiment on the Internet.

[6] Ambrus, Attila. (2014). Gradual Bidding In Ebay-like Auctions - Duke University. public.econ.duke.edu/ aa231/Gradualbid23-3.pdf.

[7] Chan, Tat \& Lu, Kai \& Wei, Zaiyan. (2019). Information Asymmetry and Strategic Early Bidding in Peer-to-Peer Lending. SSRN Electronic Journal. 10.2139/ssrn.3403211.

[8] GONZALEZ, RAUL \& Hasker, Kevin \& Sickles, Robin. (2009). An Analysis of Strategic Behavior in eBay Auctions. The Singapore Economic Review (SER). 54. 441-472. 10.1142/S0217590809003422.

[9] Ely, Jeffrey C., and Tanjim Hossain. (2009). "Sniping and Squatting in Auction Markets." American Economic Journal: Microeconomics, 1 (2): 68-94. DOI: $10.1257 / \mathrm{mic} .1 .2 .68$
[10] Gönül, Füsun \& Popkowski Leszczyc, Peter. (2011). Sniping Bidding Behavior in Ebay Auctions. International Journal of Electronic Marketing and Retailing. 1. 16-29.

[11] Halton, C. (2018). An Empirical Analysis into the Determinants of eBay Auction Market Closing Prices.

[12] Jérémie Gallien, Shobhit Gupta Temporary and Permanent Buyout Prices in Online Auctions. Management Science $53 \quad$ (5) 814-833 https://doi.org/10.1287/mnsc.1060.0650

[13] Chen, K., Ho, S., Liu, C., \& Wang, C. (2017). THE OPTIMAL LISTING STRATEGIES IN ONLINE AUCTIONS. $<$ i $>$ International Economic Review, $</ \mathrm{i}>\quad<\mathrm{i}>58</ \mathrm{i}>(2)$, 421-437. Retrieved September 11, 2021, from http://www.jstor.org/stable/44280180

[14] Chen, K.-P., Lai, H.-pin, \& Yu, Y.-T. (2017, November 24). The seller's listing strategy in online auctions: Evidence from eBay. International Journal of Industrial Organization. Retrieved September 11, 2021, from https://www.sciencedirect.com/science/article/abs/ pii/S0167718716303198\%C2\%A0.

[15] Kirkegaard, R., \& Overgaard, P. (2008). Buy-Out Prices in Auctions: Seller Competition and MultiUnit Demands. $<\mathrm{i}>$ The RAND Journal of Economics, $</ \mathrm{i}><\mathrm{i}>39</ \mathrm{i}>(3), 770-789$. Retrieved September 11, 2021, from http://www.jstor.org/stable/25474396

[16] Decision making approaches for online auction with a permanent buyout option. IEEE Xplore. (n.d.). Retrieved September 11, 2021, from https://ieeexplore.ieee.org/document/8407678\%C2 $\% \mathrm{~A} 0$.

[17] Gregg, D., \& Walczak, S. (2008). Dressing Your Online Auction Business for Success: An Experiment Comparing Two eBay Businesses. $<\mathrm{i}>$ MIS Quarterly, $</ \mathrm{i}>\quad<\mathrm{i}>32</ \mathrm{i}>(3), 653-670$. doi: $10.2307 / 25148860$

[18] Guo, Xin. (2002). An Optimal Strategy for Sellers in an Online Auction. ACM Trans. Internet Techn.. 2. $1-13$ $10.1145 / 503334.503335$ https://www.researchgate.net/publication/2201698 80_An_Optimal_Strategy_for_Sellers_in_an_Onli ne_Auction

[19] Yu Min. (2011). Study on Pricing Model of Online Auction under Competitive Strategy. http://www.jsoftware.us/vol6/jsw0602-15.pdf

[20] Song Yao. (2009). Online Auction Markets. https://dukespace.lib.duke.edu/dspace/bitstream/ha 
ndle/10161/1073/D_Yao_Song_a_200904.pdf?seq uence $=1 \&$ isAllowed $=y$

[21] Reza HABIBI. (2019). A NOTE ON STOPPING STRATEGY OF AUCTION: MAXIMIZATION SELLER GAIN PERSPECTIVE. https://www.upicardie.fr/eastwest/fichiers/art241.pdf

[22] Teacher, Law. (November 2013). Protection of Consumers in Auction Websites. Retrieved from

[23] To, P., Liao, C., Liu, Y., \& Chen, C. (2008). Online Auction Effectiveness: Optimal Selling Strategies for Online Auction Market. PACIS.

[24] Jesse Bockstedt, \&Kim Huat Goh. (2014) Seller Strategies for Differentiation in Highly Competitive Online Auction Markets. https://www.tandfonline.com/doi/abs/10.2753/MIS 0742-1222280307 